\title{
Exposure Directionality
}

National Cancer Institute

\section{Source}

National Cancer Institute. Exposure Directionality. NCI Thesaurus. Code C123945.

A qualifier for the direction on the body the exposure assessment is performed. 